\title{
A Novel Approach to Augment the Opto-Electronic Properties of Stannic Oxide (SnO2) Thin Films by Vanadium Doping
}

\author{
A. Victor Babu*,1, S. Murugan ${ }^{1}$, D.C. Bernice Victoria ${ }^{2}$ \\ ${ }^{1}$ A.V.C. College Autonomous, (Affiliated to Bharathidasan University, Tiruchirappalli), Mannampandal, 609305, India \\ ${ }^{2}$ Department of Physics, TELC School of Higher Education, Pudukkottai, 622003, India
}

\begin{tabular}{l} 
A R T I C L E I N F O \\
\hline Article history: \\
Received: 28 August, 2020 \\
Accepted: 23 October, 2020 \\
Online: 08 November, 2020 \\
\hline Keywords: \\
Doping Concentration \\
Optical Properties \\
SnO ${ }_{2}$ Thin films \\
Spray Pyrolysis \\
\end{tabular}

\begin{abstract}
A B S T R A C T
The Tin Oxide: Vanadium ( $\mathrm{SnO}_{2}: \mathrm{V}$ ) thin films have been deposited on glass substrates with various Vanadium concentration at a substrate temperature; $500^{\circ} \mathrm{C}$ using microprocessorcontrolled spray pyrolysis technique. The structural, compositional, morphological and optical analyses of the samples are characterized by XRD, EDAX, SEM and UV-Visible spectroscopy. The XRD analysis shows tetragonal rutile structure formation in lattice configuration of virgin and Vanadium doped $\mathrm{SnO}_{2}$ thin films. The uniform crystallinity is appeared on the surface of crystal and it is proved by extreme diffraction peak for $3 a t \%$ Vanadium doped $\mathrm{SnO}_{2}$ thin films. The optical transmittance increases from virgin to $3 a t \%$ with increase in doping concentration. The transmittance for $4 a t \%$ is minimum compared with $3 a t \%$ of vanadium doping. The FTIR analysis illustrates the bond formation between $\mathrm{Sn}-\mathrm{O}$ and $\mathrm{V}-\mathrm{O}$ respectively. This also validates the strong force constant for the consistent crystal structure.
\end{abstract}

\section{Introduction}

Thin film technologies paved the way of preparing the most promising material [Transparent conducting oxides] in optical energy controlled electronic devices; solar cells, displays, optoelectronic interfaces devices and electronic-circuitries, owing to its properties such as electrically conductive nature with high transmittance of light [1]. The accomplishment of such properties is performed by successive doping with wide-band gap optical semiconductors $\left(\mathrm{E}_{\mathrm{g}}>3.1 \mathrm{eV}\right)$ and are pivoted to advanced technologies[2-5]. $\mathrm{In}_{2} \mathrm{O}_{3}$ is considered to be the leading TCO in concerned with their properties as well as its commercial success. However, ITO is playing a major role in electronics market; it is of high cost and limited availability [6-9]. $\mathrm{SnO}_{2}$ is economically cheap compared to indium oxide. It is an ideal candidate for many applications. Its high chemical stability is considered to be an inherent advantage of $\mathrm{SnO}_{2}$ [10] and it makes $\mathrm{SnO}_{2}$ appreciably adoptable for applications in challenging atmosphere, for preparing transparent and strong-conductive electrode on photo enabled electrodes or as a selectively solar energy penetration coating $[11,12]$. Its applications include surface coatings, environmental and human health [13] gas sensors [14] organic

${ }^{*}$ Corresponding Author: A. Victor Babu, A.V.C. College (Autonomous), Mannampandal, Email: victornicy@gmail.com pollutants and toxic water [15] and heterojunction catalysts [16], Tin dioxide $\left(\mathrm{SnO}_{2}\right)$, having lattice parameters $\mathrm{a}=\mathrm{b}=4.737 \AA$ and $\mathrm{c}=3.826 \AA$ with tetragonal Rutile structure is an important n-type semiconductor. Each tin atom at the corners of a regular octahedron is bounded to six oxygen atoms and three tin atoms surround each oxygen atom [17]. High ability to let incoming radiation in the UV region, high reflectance in the IR region, high electrical conductivity, high melting temperature, harmless nature, easy doping and plenty in nature. These are the remarkable characteristics of $\mathrm{SnO}_{2}$ [18]. For optoelectronic devices and solar cell applications, $\mathrm{SnO}_{2}$ thin films is a very suitable candidate as it is having a good electrical and optical properties [19].

Many research investigations have been performed on heavily doped and rather doped tin oxide thin films using various available techniques [20-22]. Although there are several techniques for deposition, spray pyrolysis technique is the most preferred technique due to its simplicity, low cost and for large area coating [23]. Doping with certain $\mathrm{p}$ block and d block elements augments the light sensitive properties and the ability of transmitting electricity of $\mathrm{SnO}_{2}$ thin films [24]. As the ionic radius of Vanadium $\left(\mathrm{V}^{+} / \mathrm{Sn} 4^{+}=0.58 / 0.71 \AA\right)$ is smaller than the host $\mathrm{Sn} 4^{+}$, it can be easily doped into $\mathrm{SnO}_{2}$ [25]. After screening the literatures, it is revealed that, few researches have analyzed the 
properties of Vanadium fused $\mathrm{SnO}_{2}$ thin films [26-28], it is of particular interest to deposit Vanadium doped $\mathrm{SnO}_{2}$ thin films by micro controller-assembled spray pyrolysis technique. In the present work, the Vanadium doped $\mathrm{SnO}_{2}$ thin films have been characterized and they are investigated according to the operated properties. As a first step $\mathrm{SnO}_{2}$ : V thin films are synthesized. Then structural and light sensitive properties of the customized thinfilms are keenly observed and the data is validated. This work intends to improve the characteristics of $\mathrm{SnO}_{2}$ thin films by doping Vanadium at different concentration.

\section{Experimental methods}

\subsection{Synthesis of vanadium doped $\mathrm{SnO}_{2}$ thin films}

In the blended mixture of doubly de-ionized water and intensive solvent; methanol in the ratio 1:1, the precursor material $\mathrm{SnCl}_{4} .5 \mathrm{H}_{2} \mathrm{O}$ (Tin (IV) Chloride Pentahydrate) (35.06g) is dissolved to obtain $0.1 \mathrm{M}$ starting solution and few drops of hydrochloric acid is added to get a clear solution. To the precursor, well grained powder $\mathrm{V}_{2} \mathrm{O}_{5}$ (Vanadium Pentoxide) is added in the ratio of $0,1,2,3 \& 4 \mathrm{at} \%(0 \mathrm{~g}, 0.509 \mathrm{~g}, 1.018 \mathrm{~g}, 1.527 \mathrm{~g}, 2.036 \mathrm{~g})$. A reservoir filled with precursor solution is mounted on stand. The area of the substrate is $2.5 \times 7.5 \mathrm{~cm}^{2}$ (optically flat glass slides). Formerly cleaning of the substrates are achieved using hydrochloric acid, non-polar solvent; acetone and sterilized water by suitable ultrasonic cleaner for 35 minutes to terminate organic substance and another contaminant from the surface.

The micro controller-operated spray pyrolysis set up is displayed in Figure1. It consists of a syringe needle having the diameter of $0.6 \mathrm{~mm}$ connected to the reservoir and its height can be altered to get $0.002 \mathrm{~mL} / \mathrm{Min}$ at the needle tip. Distance of $8 \mathrm{~cm}$ is kept between the needle and the surface of the substrate. Substrate attracts the precursor solution as high voltage of about $(9.65 \mathrm{KV})$ is applied between needle and hot-plate. To optimize the thickness $(500 \mathrm{~nm})$ different volume of precursor solution is sprayed and the dimensions between the two surfaces of all the sprayed samples are verified using standard method. A timer is connected to high voltage power supply, relay and hot plate. The timer is set in such a way that when hot plate is on, high voltage will be in off condition and vice-versa. The charge presents in substrate holder and syringe needle, substrate temperature, heat inside the chamber are controlled by means of relay, thermocouple arrangement and exhaust fan. The distance of the syringe needle is adjusted up and down to obtain a continuous thin film. In the experiment, five sequential sets of undoped and Vanadium doped $\mathrm{SnO}_{2}$ thin films are fabricated by controlling the substrate temperature at $500^{\circ} \mathrm{C}$. The optimized time allotment for deposition for each sample is determined as 44 minutes by counting the spray intervals of time. The alternating spray process is employed for this study at a spray for 5seconds and an interval of 10 seconds for each cycle.

\subsection{Characterization Technique}

In our present study the surface morphology of the prepared samples is characterized by employing scanning electron microscope (CARLZEISS) shown in Figure 2. The compositional details are analyzed by (EDAX) technique. The lattice parameters are examined by X-ray diffractometer (SHIMADZU-XRD 6000) $(\mathrm{Cu}-\mathrm{Ka})$ of wavelength $1.520 \AA$. The profilometer is used to find the dimension between two surfaces of the films by making suitable stylus technique at four different areas on the outside of film and the average dimension is found to be around $500 \mathrm{~nm}$. Weight gain method is also used to find the thickness. The optical absorption and translucence of the films are measured in the wavelength range of $300-1100 \mathrm{~nm}$ using a Unico $4802 \mathrm{UV}-\mathrm{Vis}$ double beam spectrophotometer. FTIR spectra are recorded by means of SHIMADZU1800-UV Fourier transform infrared spectrometer.

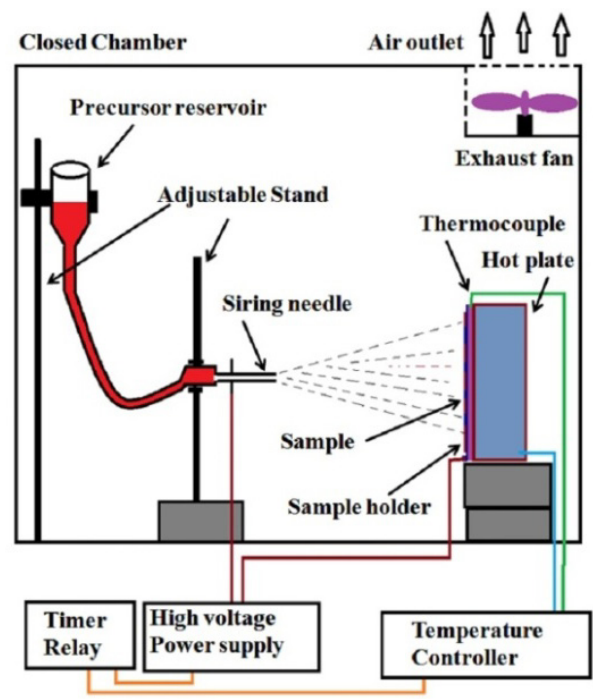

Figure 1: Schematic diagram of the Home-made spray pyrolysis setup.

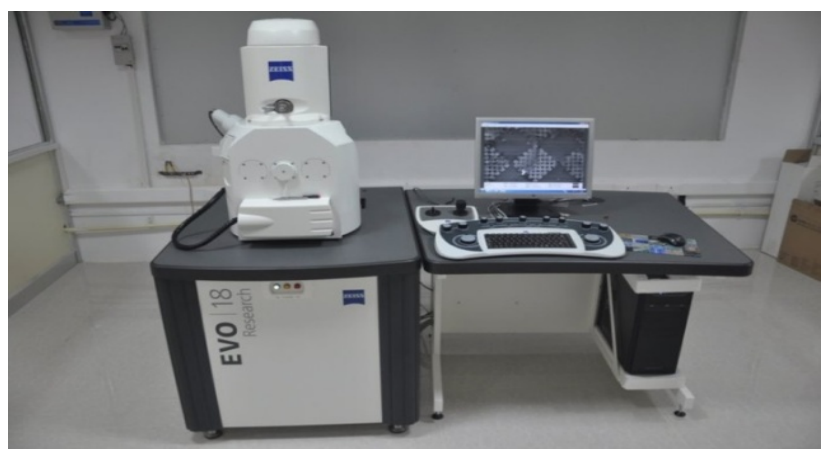

Figure 2: Carl Zeiss scanning electron microscope.

\section{Results and Discussion}

\subsection{Structural properties}

Figure 3 shows the XRD spectra of virgin and Vanadium doped $\mathrm{SnO}_{2}$ thin films. The highest diffraction peaks are (110), (101), (200), (211), (220). The coincidence of diffracted peaks with tetragonal structure of $\mathrm{SnO}_{2}$ (JCPDS card number: 41-1445) is observed for all the recorded peaks of Vanadium doped $\mathrm{SnO}_{2}$ thin films [29]. No phase consistent to the dopant or other compound is observed. Though the doping level of Vanadium is increased from $1 \mathrm{at} \%$ to $3 \mathrm{at} \%$, Vanadium oxide phases are not 
dominated in Vanadium operated $\mathrm{SnO}_{2}$ films. The intensity of the peak corresponding to the predominant plane (110) in the primary phase is increased on Vanadium doping until 3at $\%$ and further addition of 1 at $\%$ doping concentration, the intensity decreases due to the exchange of $\mathrm{Sn}^{+}$ions with Vanadium ions in the lattice of $\mathrm{SnO}_{2}$ film, whereas the intensity of the plane (211) in the secondary phase rapidly increases with increase in the concentration of Vanadium. This shows better atomic arrangement and lower scattering in these planes. The structural analysis is done for the predominant peak and the results are given in Table 1. The optimized crystallite size of virgin $\mathrm{SnO}_{2}$ and doped $\mathrm{SnO}_{2}$ films for all the dopant levels are calculated using Debye-Scherrer formula [30]

$$
\mathrm{D}=\mathrm{K} \lambda / \beta \cos \theta
$$

where $\mathrm{D}$ is the mean crystallite size, $\mathrm{K}$ is a particle size dependent constant whose value is $0.9, \lambda$ is the diffraction wavelength of $\mathrm{CuKa}(\lambda=1.5406 \AA) . \beta$ is the full width at half maximum (FWHM) and $\theta$ is the diffracted angle. The lattice parameters and crystallite size for the predominant peak (110) of the prepared samples are given in Table1. It is confirmed that the increase in the concentration of Vanadium from 0 to $4 \mathrm{at} \%$ results in the range of crystallite size from $55.72 \mathrm{~nm}$ to $41.79 \mathrm{~nm}$. The decrease in crystallite size may be due to the density enrichment in the nucleation centers of the doped samples and also may be due to lattice distortion. For further addition of $1 \mathrm{at} \%$ Vanadium, dopant dominates the crystalline size.

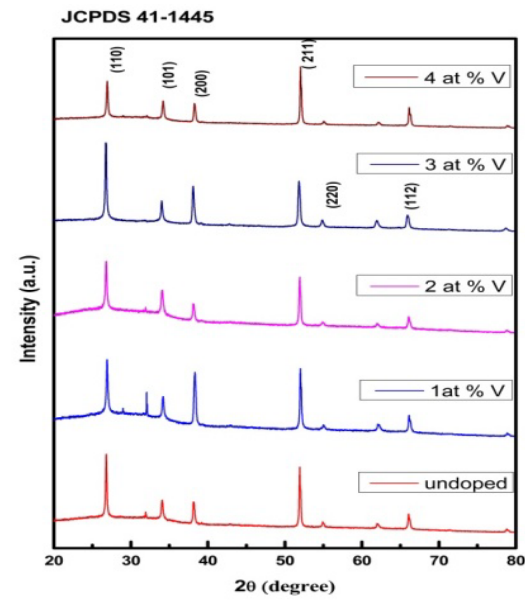

Figure 3: XRD Pattern of undoped and V (1at $\%$, 2at $\%$, 3at $\%$, 4at $\%$ ) doped $\mathrm{SnO}_{2}$ thin films.

Table 1: Doping concentration ratio (1at $\%$, 2at $\%$, 3at $\%$, 4at $\%)$ for $\mathrm{SnO}_{2}$ thin films.

\begin{tabular}{|l|l|c|l|l|}
\hline $\begin{array}{c}\text { Predominant } \\
\text { peak }\end{array}$ & $\begin{array}{c}\text { Angle20 } \\
(\text { degree })\end{array}$ & $\begin{array}{c}\mathrm{d} \\
\text { spacing } \\
(\hat{\AA})\end{array}$ & FWHM & $\begin{array}{c}\text { Crystallite } \\
\text { size (nm) }\end{array}$ \\
\hline $\begin{array}{l}\text { Undoped } \\
(110)\end{array}$ & 26.806 & 3.3232 & 0.153 & 55.72 \\
\hline $\begin{array}{l}\text { 1at\%V } \\
(110)\end{array}$ & 26.908 & 3.3107 & 0.180 & 47.37 \\
\hline
\end{tabular}

\begin{tabular}{|l|l|l|l|l|}
\hline $\begin{array}{l}\text { 2at\%V } \\
(110)\end{array}$ & 26.932 & 3.3079 & 0.175 & 48.73 \\
\hline $\begin{array}{l}3 \mathrm{at} \% \mathrm{~V} \\
(110)\end{array}$ & 26.793 & 3.3248 & 0.204 & 41.79 \\
\hline $\begin{array}{l}4 \mathrm{at} \% \mathrm{~V} \\
(110)\end{array}$ & 26.748 & 3.3302 & 0.172 & 49.76 \\
\hline
\end{tabular}

\subsection{Morphological Analysis}

The surface morphology of virgin and Vanadium doped $\mathrm{SnO}_{2}$ thin films deposited at a temperature of $500^{\circ} \mathrm{C}$ with different Vanadium content concentration are shown in Figure 4. The SEM image of virgin $\mathrm{SnO}_{2}$ exhibits smaller grains. It is evident from the images that the surface morphology reveals significant changes on doping [31]. For 1 at $\%$ of Vanadium doped $\mathrm{SnO}_{2}$ thin film, molecules of different morphology and sizes are formatted due to inadequate Vanadium doping. Grain size decreases when doping concentration of Vanadium increases [32]. This is observed in the SEM image for $2 \mathrm{at} \%$ Vanadium doped $\mathrm{SnO}_{2}$ thin film. A film having superior quality with uniform grains as proved by structural analysis is observed for 3at\% Vanadium doped $\mathrm{SnO}_{2}$ thin film. Above $3 a t \%$ of the dopant concentration, grains are found to increase in its size and appear with small sized grains in between large sized grains.

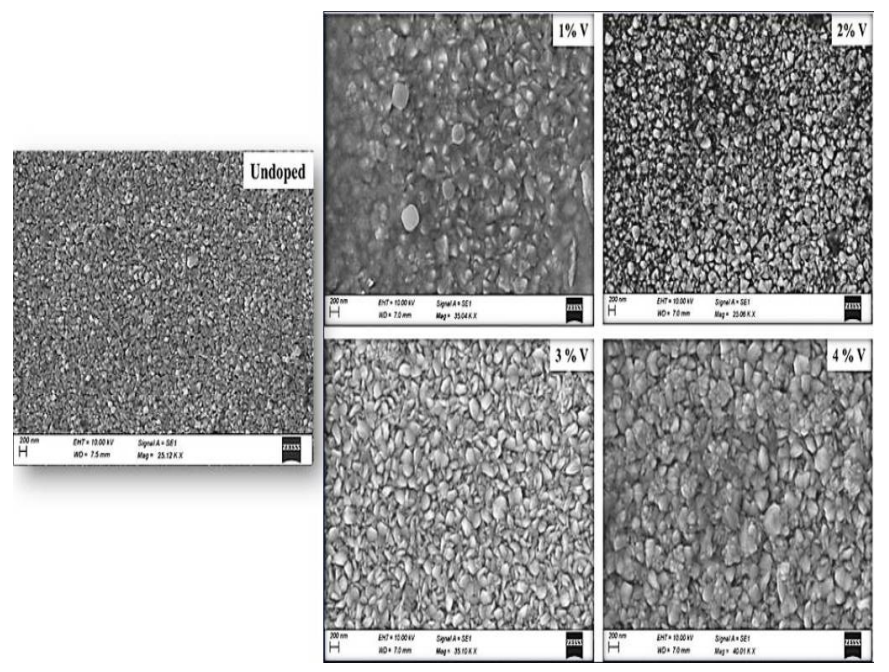

Figure 4: SEM images of undoped and $\mathrm{V}(1 \mathrm{at} \%, 2 \mathrm{at} \%, 3 \mathrm{at} \%, 4 \mathrm{at} \%)$ doped $\mathrm{SnO}_{2}$ thin films.

\subsection{Elemental analysis}

From the EDAX analysis recorded in Figure 5. The consistent peaks $\mathrm{Sn}, \mathrm{V}$ and $\mathrm{O}$ are observed in the EDAX pattern of all the Vanadium doped samples. For all V-doped $\mathrm{SnO}_{2}$ samples the existence of Vanadium is also detected. Both vanadium extent and relative intensity are directly proportional to each other.

\subsection{Optical properties}

Optical transmittance spectra of virgin and Vanadium doped $\mathrm{SnO}_{2}$ thin films are shown in Figure 6. In the visible region (400$700 \mathrm{~nm}$ ), the observed translucence is about $\sim 60-80 \%$. For virgin $\mathrm{SnO}_{2}$ thin film transmittance is minimum compared to the vanadium doped $\mathrm{SnO}_{2}$ thin film. Transmittance increases with dopant concentration. Increase in transmittance may be due to the 
improved crystallinity of the film. In our results, transmittance increases from virgin to $3 \mathrm{at} \%$ with increase in dopant concentration. Transmittance decreases with further 1 at $\%$ of Vanadium doping. The decrement of optical transmittance is made due to the increment of particle size and it is evidenced from the SEM image and also may be due to the crystal defects created by doping.

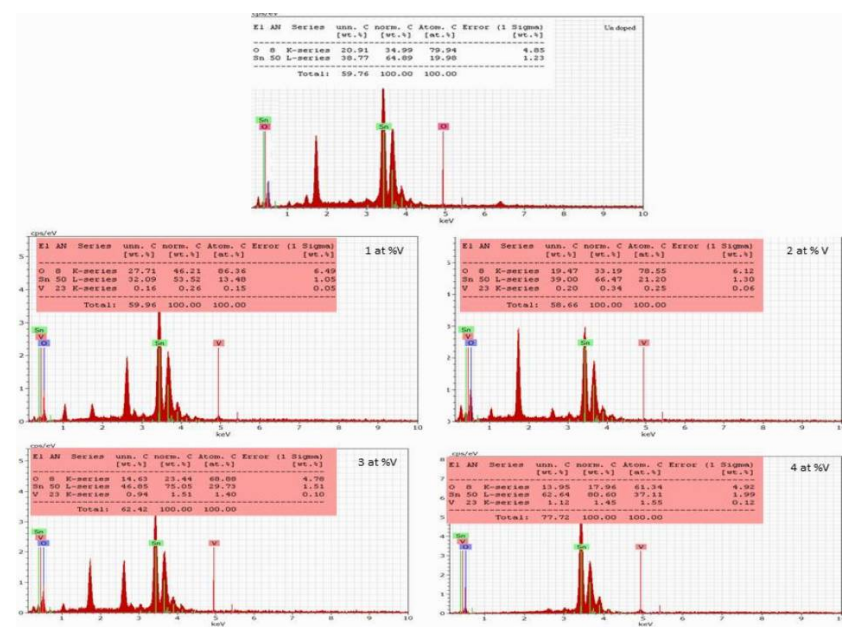

Figure 5: EDAX analysis spectra of undoped and V (1at $\%$, 2at $\%$, 3at $\%$, 4at \%) doped $\mathrm{SnO}_{2}$ thin films.

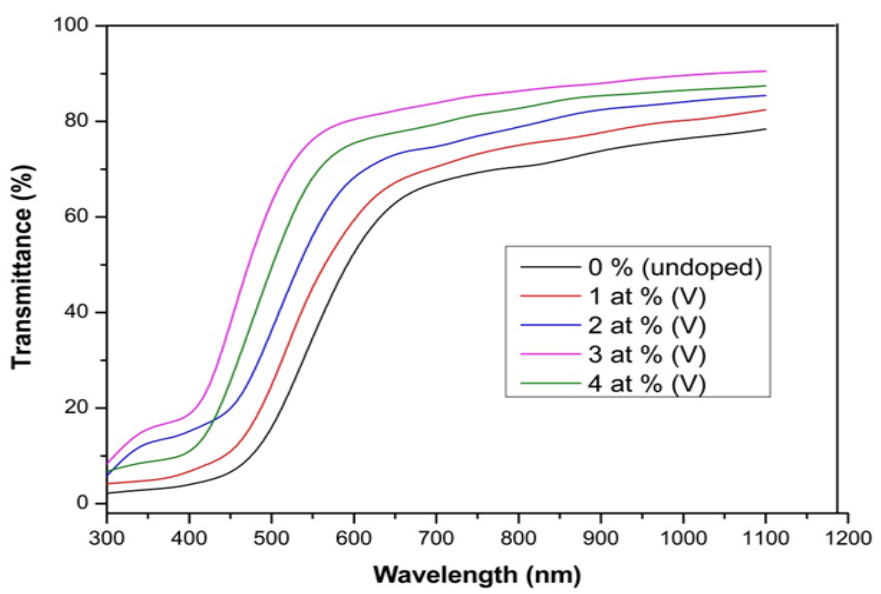

Figure 6: Transmittance spectra of undoped and V (1at $\%, 2 \mathrm{at} \%$, 3at $\%$, 4at $\%)$ doped $\mathrm{SnO}_{2}$ thin films.

The observed absorbance modulated spectra of virgin $\mathrm{SnO}_{2}$ and Vanadium doped $\mathrm{SnO}_{2}$ thin films at different concentrations are depicted in Figure 7. Gradually increasing absorption from NIR to the visible region is observed. The absorption edge is prolonged to the visible region due to the fusion of Vanadium ions into $\mathrm{SnO}_{2}$ ions. A substantial red-shift is absolutely observed on the increment in doping attentiveness of vanadium species [33]. Absorption band edge of the films is observed by the calculated first derivative of the optical transmittance. The band gap is an important property which determines the quality of the deposited thin films. In Figure 8, the curves of dT/d $\lambda$ vs h $v$ have been drawn and showed the stress of doping on the direct optical band gap $(\mathrm{Eg})$.The band gap values are observed to be ranged from 2.970 $\mathrm{eV}$ to $3.130 \mathrm{eV}$. There is fluctuation in band gap energies with doping concentrations of Vanadium. High value of band gap energy is a result of lower-quality films. In the present case good quality film is obtained in $3 a t \%$ of Vanadium doping concentration.

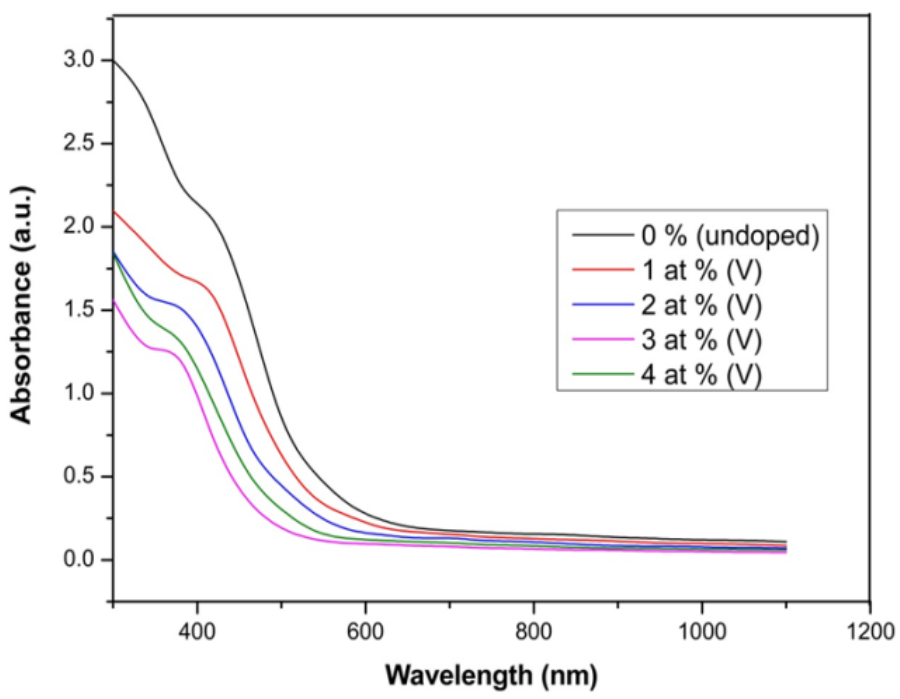

Figure 7: Absorption spectra of undoped and V (1at $\%$, 2at $\%$, 3at $\%$, 4at $\%$ ) doped $\mathrm{SnO}_{2}$ thin films.

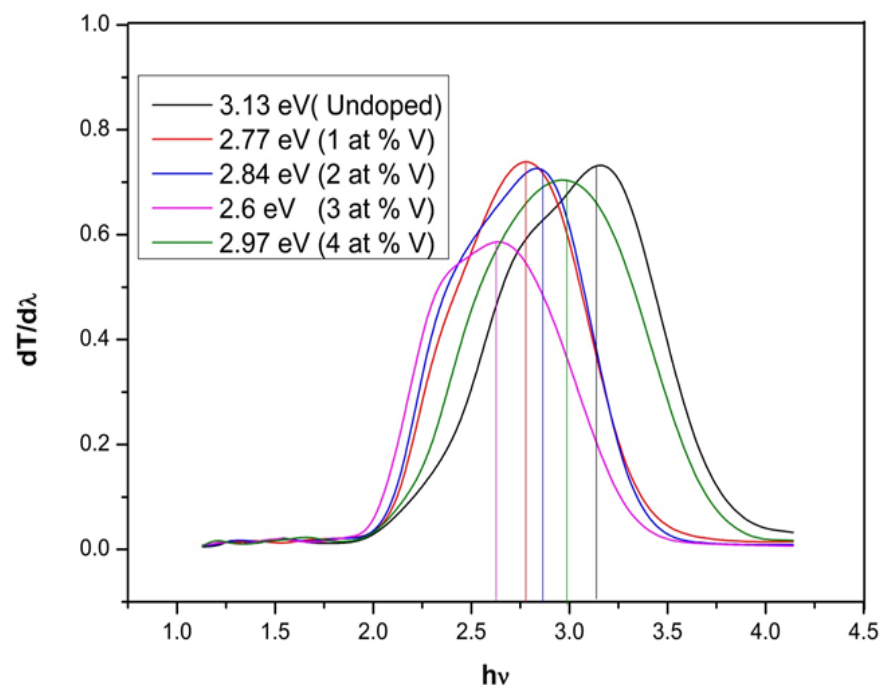

Figure 8: Plot of $\mathrm{dT} / \mathrm{d} \lambda$ vs. (hv) for undoped and V (1at $\%$, 2at $\%$, 3at $\%$, 4at $\%)$ doped $\mathrm{SnO}_{2}$ thin films.

\subsection{FTIR analysis}

Figure 9 displays the FT-IR spectra of virgin and Vanadium doped $\mathrm{SnO}_{2}$ thin films fabricated by microprocessor-controlled spray pyrolysis method. As the present case is inorganic compound, all the IR peaks are concentrated in the region of $200-1200 \mathrm{~cm}^{-1}$. Particularly, the stretching, in plane and out of plane bending modes for Sn-O bond are observed at 750,740 and $710 \mathrm{~cm}^{-1}$, the in plane bending modes are found at 400,380 and $360 \mathrm{~cm}^{-1}$ and the out of plane bending modes are occupied at 280,260 and $250 \mathrm{~cm}^{-1}$. All the observed bands are validated by the literatures [34]. The V$\mathrm{O}$ bond stretching, bending modes are determined at 610,320 and $210 \mathrm{~cm}^{-1}$. All the spectroscopical impressions illustrate the strong coupling of $\mathrm{V}$ on $\mathrm{SnO}_{2}$ configuration. 


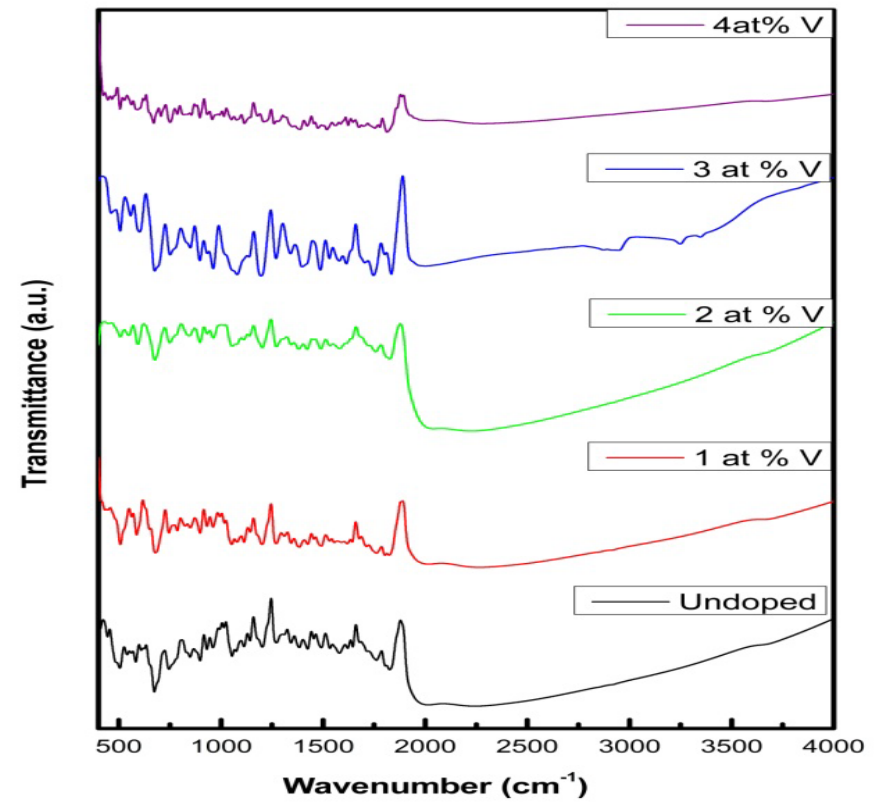

Figure 9: FTIR spectra of undoped and V (1at $\%$, 2at $\%$, 3at $\%$, 4at $\%)$ doped $\mathrm{SnO}_{2}$ thin films.

\section{Conclusions}

In this work, the popular heavy metal species Vanadium is doped on $\mathrm{SnO}_{2}$ crystal material and it is formed as thin films with the doping concentration of $1 \mathrm{at} \%, 2 \mathrm{at} \%, 3 \mathrm{at} \%$ and $4 \mathrm{at} \%$ respectively. The compositional, morphological, structural and optical analysis is made on samples and the results are discussed. From the observed data, the optimized state of doping concentration is found to be $3 \mathrm{at} \%$. The vibrational study is confirmed the active presence of strong bonds such as Sn-O and $\mathrm{V}-\mathrm{O}$. The presence of Sn-O-V bonds and angles are also validated from the complex form of vibrational bands. The film at doping of 3 at $\%$ is having superior quality with uniform grains as proved by structural. From the optical studies, it is revealed that, the optical intensive transmittance increases from virgin to doped $\mathrm{SnO}_{2}$ at 3 at $\%$ which leads to the decrement of band gap energy. The acquired results from structural, morphological, vibrational and optical studies demonstrated the effectiveness of doped thin film.

\section{Acknowledgment}

The authors gratefully acknowledge to Alagappa University and Kalasalingam University for providing the facilities to characterize the samples.

\section{References}

[1] A. Stadler, "Transparent Conducting Oxides-An Up-To-Date Overview," Materials, 5(4), 661-683, 2012, doi: 10.3390/ma5040661.

[2] S.C. Dixon, D.O.Scanlon, C.J.Carmalt, I.P.Parkin, "N-Type doped Transparent conducting binary oxides: an overview," Journal of Chemical, 4(29), 6946-6961, 2016, doi: 10.1039/C6TC01881E.

[3] P. Ivan Parkin, D. Troy Manning, "Intelligent thermo chromic windows," Journal of Chemical Education, 83(3), 393-400, 2006. doi: 10.1021/ed083p393.

[4] S. Das, V. Jayaraman, " $\mathrm{SnO}_{2}$ : A comprehensive review on structures and gas sensors," Progress Materials Science, 66(23), 112-255, 2014, doi: 10.1016/j.pmatsci.2014.10.001.
[5] Hosono, "Recent progress in transparent oxide semiconductors: Materials and device application," Thin Solid Films, 515(15), 6000-6014, 2007, doi: 10.1016/j.tsf.2006.12.125.

[6] M. Aliyu, S. Hossain, J. Husna, N. Dhar, M.Q. Huda, K. Sopian, N. Amin, "High quality indium tin oxide (ITO) film growth by controlling pressure in RF magnetron sputtering," $38^{\text {th }}$ IEEE Photovoltaic Specialists Conference; IEEE, 002009-002013, 2012, doi: 10.1109/PVSC.2012.6317992.

[7] R. Gupta, K. Ghosh, S. Mishra, P. Kahol, "Structural, optical and electrical characterization of highly conducting Mo-doped $\mathrm{In}_{2} \mathrm{O}_{3}$ thin films," Applied Surface Science, 254(13), 4018-4023, 2008, doi: 10.1016/j.apsusc.2007.12.035.

[8] T. Minami, "New n-Type Transparent Conducting Oxides, MRS Bulletin, 25(8), 38-44, 2000, doi: 10.1557/mrs2000.149.

[9] A. Benjamin, D. Williamson, Thomas J. Featherstone,Sanjayan S. Sathasivam, Jack E. N. Swallow, Huw Shiel, Leanne A. H. Jones, Matthew J. Smiles, Anna Regoutz, Tien-Lin Lee, Xueming Xia, Christopher Blackman, Pardeep K. Thakur, Claire J. Carmalt, Ivan P. Parkin, Tim D. Veal and David O. Scanlon, "Resonant Ta Doping for Enhanced Mobility in Transparent Conducting $\mathrm{SnO}_{2}$," Chem. Mater. 32(5), 1964-1973, 2020, doi: 10.1021/acs.chemmater.9b04845.

[10] J.L. Vossen, Kern.W, (Eds.) Thin Film Processes II; Academic Press: Cambridge, MA, USA, 1991

[11] F. Lungwitz, Ramon Escobar-Galindo, Daniel Janke, Erik Schumann, Robert Wenisch, Sibylle Gemming, Matthias Krause, "Transparent conductive tantalum doped tin oxide as selectively solar transmitting coating for high temperature solar thermal applications," Solar Energy Materials Solar Cells, 196(1), 84-93, 2019, doi: 10.1016/j.solmat.2019.03.012.

[12] L. Kavan, L. Steier, Michael Grätzel, "Ultrathin Buer Layers of $\mathrm{SnO}_{2}$ by Atomic Layer Deposition: Perfect Blocking Function and Thermal Stability," The Journal of Physical Chemistry C, 121(1), 342-350. 2017, doi: 10.1021/acs.jpcc.6b09965.

[13] T. Chang, X. Cao, Shan-Hu Bao, Shi-Dong Ji, Hong-Jie Luo, Ping Jin,"Review on thermochromic vanadium dioxide based smart coatings: from lab to commercial application," Advances Manufacturing, 6(1), 1-19, 2018, doi:10.1007/s40436-017-0209-2.

[14] C. Wang, Miao-Ting Chen, D. Lai, "Vanadium tin oxide nanoparticles with gas sensing and catalytic activity," Journal of the American Ceramic Society, 94(12), 4471-4477, 2011, doi.10.1111/j.1551-2916.2011.04733.x.

[15] M. Wei, X. Peng, Qi-Sheng Liu, Fang Li, Ming-Ming Yao, "Nano crystalline $\mathrm{TiO}_{2}$ composite films for the photo degradation of formaldehyde and oxytetracycline under visible light irradiation," Molecules, 22(6), 1-13, 2017, doi:10.3390/molecules22060950.

[16] K.H. Abass, M. Mohammed, "Fabrication of $\mathrm{ZnO}$ : Al/Si Solar Cell and Enhancement its Efficiency Via Al-Doping," Nano Biomedicine and Engineering, 11(2), 170- 177, 2019, doi.10.5101/nbe.v11i2.p170-177.

[17] W. Cai-hong, Xiangfeng Chu, M.Wu, "Highly sensitive gas sensors based on hollow $\mathrm{SnO}_{2}$ spheres prepared by carbon sphere template method," Sensors and Actuators B Chemical, 120(2), 508-513, 2007, doi: 10.1016/j.snb.2006.03.004.

[18] D.S. Ginley, Clark Bright, "Transparent Conducting Oxides," MRS Bulletin, 25(8), $15-18,2000$, doi:10.1557/mrs2000.256.

[19] A. Abdelkrim, S. Rahmane, "Optoelectronic properties of $\mathrm{SnO}_{2}$ thin films sprayed at different deposition times," Chinese Physics B, 25(4), 2016. doi:10.1088/1674-1056/25/4/046801.

[20] G. Sanon, R. Rup, A. Mansingh, "Band-gap narrowing and band structure in degenerate tin oxide $\left(\mathrm{SnO}_{2}\right)$ films," Physical Review B, 44(11), 5672-5680, 1991, doi: 10.1103/physrevb.44.5672.

[21] K. S. Shamala, L.C.S. Murthy, K. Narasimha Rao "Studies on tin oxide films prepared by electron beam evaporation and spray pyrolysis methods," Bulletin of Materials Science, 27(3), 295-301, 2004, doi: 10.1007/BF02708520.

[22] S. Hamzaoui, M. Adnane, "Effects of temperature and r.f. power sputtering on electrical and optical properties of $\mathrm{SnO}_{2}$," Applied Energy, 65(1-4), 1928, 2000, doi: 10.1016/S0306-2619(99)00045-8.

[23] S. Chandra, K. Ravichandran, G. George, T. Arun, P. Rajkumar, "Influence of $\mathrm{Fe}$ and $\mathrm{Fe}+\mathrm{F}$ doping on the properties of sprayed $\mathrm{SnO}_{2}$ thin films," Journal of Materials Science Materials in Electronics,27(9),9558-9564, 2016, doi: 10.1007/s10854-016-5008-1.

[24] B. Zhang, Y. Tian, J. X. Zhang and W. Cai, "The FTIR studies of $\mathrm{SnO}_{2}$ : $\mathrm{Sb}$ (ATO) films deposited by spray pyrolysis," Materials Letters. 65(8), 12041206, 2011, doi: 10.1016/j.matlet.2011.01.052.

[25] A. Popa, D. Toloman, O. Raita, M. Stan, O. Pana, T.D. Silipas, L.M. Giurgiu, "Ferromagnetic behavior of vanadium doped $\mathrm{SnO}_{2}$ nanoparticles annealed at different temperatures," Journal of Alloys and Compounds, 591, 2014, doi:10.1016/j.jallcom.2013.12.189. 
[26] W.B. Soltan, M.S. Lassoued, S. Ammar, T. Toupance, "Vanadium doped $\mathrm{SnO}_{2}$ nano particles for photo catalytic degradation of methylene blue," Journal of Materials Science Materials in Electronics, 28(4),15826-15834, 2017, doi: 10.1007/s10854-017-7477-2.

[27] J. Mazloom, F.E. Ghods, H. Golmojdeh,"Synthesis and characterization of vanadium doped $\mathrm{SnO}_{2}$ diluted magnetic semiconductor nano particles with enhanced photo catalytic activities", Journal of alloy compounds,639(1),393-399,2015, doi: 10.1016/j.jallcom.2015.03.184.

[28] R. Nasiraei, M. R. Fadavieslam, and H. Azimi-juybari, "Structural, photoconductive, thermoelectric and activation energy measurements of Vdoped transparent conductive $\mathrm{SnO}_{2}$ films fabricated by spray pyrolysis technique," Pramana Journal of Physics, 87(2), 1-10, 2016, doi: 10.1007/s12043-016-1237-3.

[29] Y. Fu, H. Ma, Zhenl ü Wang, Wanchun Zhu, Tonghao Wu, Guo-jia Wang. "Characterization and reactivity of $\mathrm{SnO}_{2}$-doped $\mathrm{V}_{2} \mathrm{O}_{5} / \gamma-\mathrm{Al}_{2} \mathrm{O}_{3}$ catalysts in dehydrogenation of isobutane to isobutene," Journal of Molecular Catalysis A: Chemical, 221(1), 163-168, 2004, doi:10.1016/j.molcata.2004.07.016.

[30] S. Chacko, N. Sajeeth Philip , K.G.Gopchandran, Peter Koshy, V.K.Vaidyan, "Nanostructural and surface morphological evolution of chemically sprayed $\mathrm{SnO}_{2}$ thin films," Applied Surface Science, 254(7), 2179-2186, 2008, doi: 10.1016/j.apsusc.2007.09.027.

[31] J.F. Chang, H.H. Kuo, I.C. Leu, M.H. Hon, "The effects of thickness and operation temperature on $\mathrm{ZnO}$ : $\mathrm{Al}$ thin film $\mathrm{CO}$ gas sensor," Sensors and Actuators B: Chemical, 84(2), 258-264, 2002, doi: 10.1016/S09254005(02)00034-5.

[32] C. Venkata Reddy, B. Babu, S.V. Prabhakar Vattikuti, R.V.S.S.N. Ravikumar, Jaesool Shim "Structure and optical properties of vanadium doped $\mathrm{SnO}_{2}$ nanoparticles with high photo catalytic activities," Journal of Luminescence, 179, 26-34, 2016, doi:10.1016/j.jlumin.2016.06.036.

[33] J. Liu, R. Yang, S. Li, "Synthesis and Photocatalytic Activity of $\mathrm{TiO}_{2} / \mathrm{V}_{2} \mathrm{O}_{5}$ Composite Catalyst Doped with Rare Earth Ions," Journal of rare Earths, 25(2), 173-178, 2007, doi: 10.1016/S1002-0721(07)60068-4.

[34] A. R. Khataee, M. B. Kasiri, "Photocatalytic degradation of organic dyes in the presence of nanostructured titanium dioxide: influence of the chemical structure of dyes," Journal of Molecular Catalysis A: Chemical, 328(1-2), 826, 2010, doi:10.1016/j.molcata.2010.05.023. 